\title{
Responsive solutions in shaping innovative architectural structures
}

\author{
Barbara Ewa Gronostajska ${ }^{1}$, Anna Maria Berbesz ${ }^{1, *}$ \\ ${ }^{1}$ Wroclaw University of Science and Technology, Faculty of Architecture, Department of Housing \\ and Industrial Architecture, Interior Design, Rural and Landscape Planning and Visual Arts W1/K6, \\ Poland
}

\begin{abstract}
Permanent technological development leads to the search for the most utilitarian material and structural solutions in architecture. During recent decades, a large number of bioinspired materials applicable in engineering and medicine have been invented. However, nature remains the perfect creator of multifunctional structures. The main question concerns the possibility of implementing technological solutions that would enable a literal moving of the building. The assumption of responsive architecture is the ability to react to the user's actions and external environmental stimulation. Nowadays, electronic systems that enable integral control of individual building installations in order to minimize energy losses (e.g. BMS) are commonly available. In kinetic and responsive architecture the CABS system is often used to control the façade. This paper focuses on the etymology of responsive architecture and outlines the directions of its application in the innovative technological solutions in architecture.
\end{abstract}

\section{The etymology of responsive architecture}

At the turn of the $20^{\text {th }}$ and $21^{\text {st }}$-century architectural considerations moved from the mechanistic field to solutions outside architecture itself (transgression of architecture) and its compilations with various fields of science. At the time, a number of new types of architecture were created, i.e. flexible, kinetic, portable or responsive architecture. In the second half of the $20^{\text {th }}$ century, a series of cities-megastructures and utopian visions were created. The motive of mobility, dynamics, and adaptable structures had a significant impact on design concepts. In the 1960s the ideas of megastructures in the activities of Yona Friedmann with the GEAM group, Archigram or Japanese Metabolists were particularly significant. These groups focused on the search for new forms of architectural structures combining the development of society with technological progress [1]. The concept of responsive architecture has been introduced in the late 1960s when the first cybernetic solutions were incorporated into architectural concepts. Nicholas Negroponte, the co-founder of the MIT Media Lab and a pioneer in the field of computer-aided design, is considered as the main creator of the concept of responsive architecture [2]. According to the analysis of responsive architecture carried out by Tristan d'Estrée Sterk, one of the

\footnotetext{
*Corresponding author: anna.berbesz@pwr.edu.pl
} 
leading designers in this field, on the theoretical assumptions of responsive architecture the activity of architectural offices such as dECOi, Nox or Diller and Scofidio was particularly important [3]. The most common definition of responsive architecture is the type of structure or the object that has an ability to change form in order to continuously respond to environmental conditions. Moreover, responsive architecture is also related to the concept of movement in architecture.

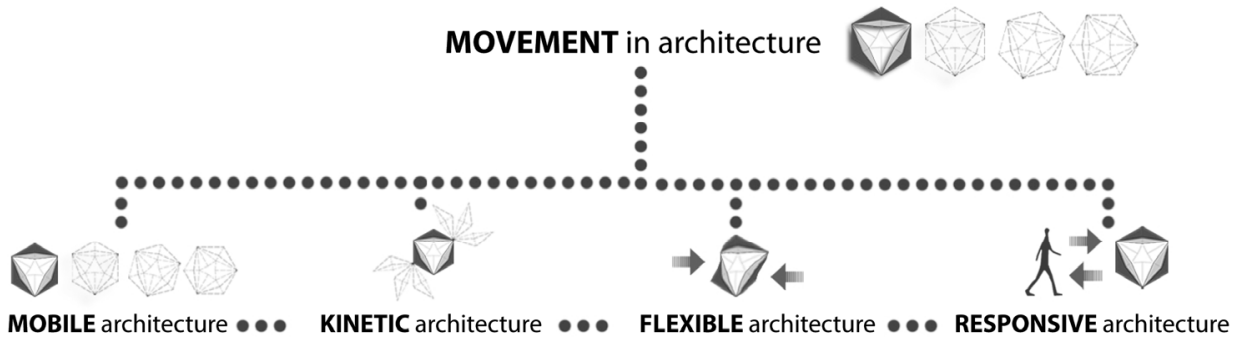

Fig. 1. Responsive architecture and its connection to the concept of movement in architecture, author: A. M. Berbesz.

\section{Electronic systems used in responsive architecture - selected solutions}

The response of a structure to external and internal factors can occur at various levels. Nowadays, electronic systems that enable integral control of individual building installations in order to minimize energy losses are commonly available. One of the most popular automation systems is BAS/BMS (Building Automation Systems / Building Management Systems). It is an advanced technical solution, whose purpose is an effective control of installations, i.e. electrical, ventilation, heating and cooling and to adapt their work to changing environmental conditions. The most important goal of the system is to minimize the operating costs of the building while ensuring optimal comfort for its users [4].

\section{$80 \%$ of energy under control}

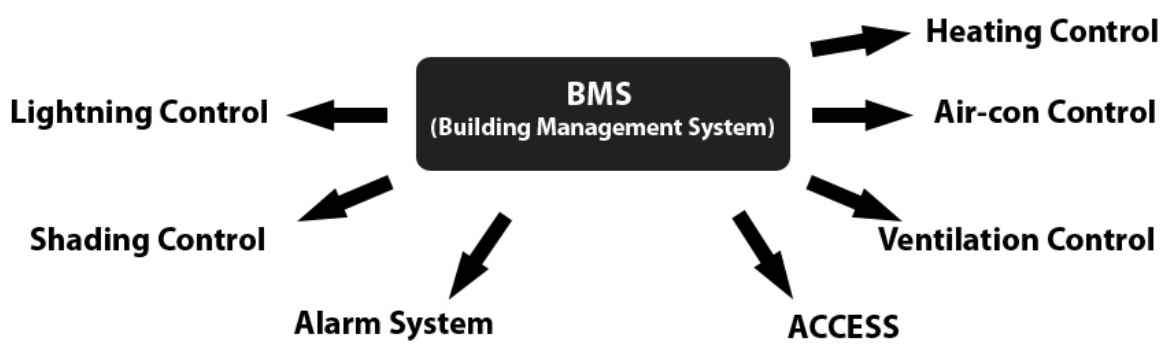

Fig. 2. Scheme of systems and energy under control in BMS (Building Management System), author: A. M. Berbesz, based on: http://www.buildingautomation.cz.

The system that is being used mainly in responsive and kinetic architecture is CABS (Climate Adaptive Building Shells) which can completely react to climate changes by using kinetic and flexible elements of the façade. According to the article: 'Climate adaptive building shells: State-of-the-art and future challenges', CABS system has the ability to reversibly and repeatedly change in order to improve the building efficiency [5]. The concept of CABS system is mostly focused on the façade of the building and is especially known as smart-façade, dynamic-façade, intelligent or active façade [6]. One of the subsystems closely related to the CABS is Active daylighting. 


\section{Selected examples of responsive architecture}

\subsection{Al Bahr Towers, UAE}

The main design idea of Al Bahr Towers was to create a double-layered external wall that would provide a comfortable interior microclimate due to high air temperatures in UAE up to $50^{\circ} \mathrm{C}$. Al Bahr Towers are part of a multi-stage zoning plan, the completion of which is being planned for 2030 .

The shape of the objects consists of two cylindrical towers on a circle plan. The circle is the most optimal and efficient shape for creating large volume buildings. In modeling of the structures, the CFD (Computational Fluid Dynamics) program was used. It is a tool that is being used in the space, ship and car industry. The geometry of the objects was designed by using parametric modeling and BIM (Building Information Modeling) system [7]. The inspiration for the implementation of external façade screens was the Arab 'Mashrabiya' which 'is made of geometric patterns providing shade whilst allowing sufficient diffused light and breeze into the building' [8]. Designers have developed a new active spatial structure, modern Mashrabiya, fastened to the façade. The PTFE (polytetrafluoroethylene) membrane has been stretched on the movable frame. The structure of the outer cover was created with the cooperation of the London office Aedas, Arup and the Research\&Development group. Initially a mock-up of several elements in a 1:1 scale was made. On two towers there are approx. 2100 movable modules with dimensions of $4 \times 6 \mathrm{~m}$ and a weight of $600 \mathrm{~kg}$. Each module has been equipped with actuators and is controlled separately. The dynamic structures have enabled the reduction of the interior insolation by $50 \%$ and the demand for electricity of climatic devices by $20 \%$.

At the top of skyscrapers, there is a terrace covered with a photovoltaic panel system providing $5 \%$ of the energy needed to operate the facility (for water heating and LEED Silver lightning supply). As a result of using environmentally friendly solutions, $\mathrm{CO}_{2}$ emission was reduced by 1,750 tons per year [7].
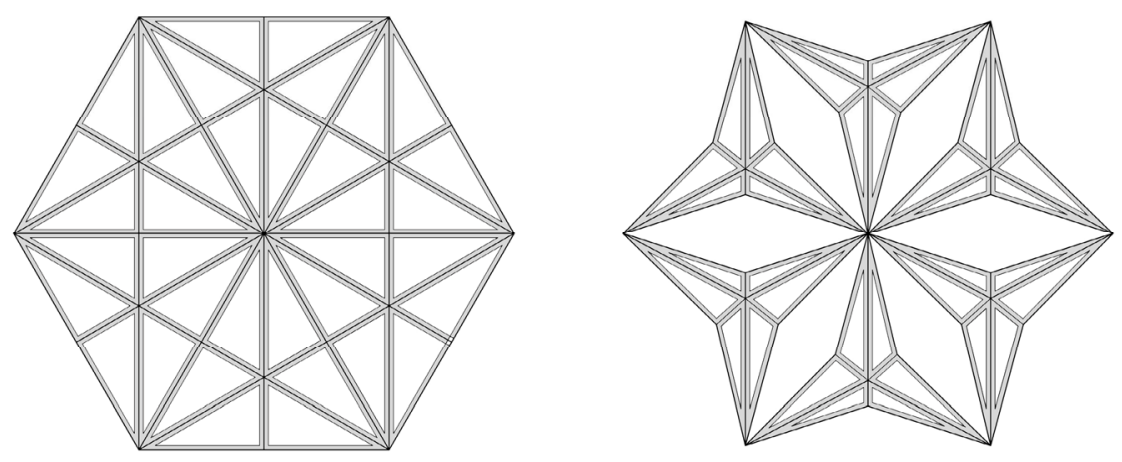

Fig. 3. Scheme of the movable modules fastened to the façade; closed element (on the left) and open (on the right), author: A. M. Berbesz,

based on: http://compositesandarchitecture.com/?attachment_id=2376

\subsection{Responsive structures: HypoSurface and Lotus Dome}

The HypoSurface by dECOi is one of the World's first display system with the physically moving screen. The system is a classic mechatronic model which typifies the majority of control applications [9]. The structure may be a part of an outer curtain wall, an internal element or a screen. 
The name HypoSurface was inspired by the concept of a hypersurface that occurs in mathematical nomenclature. A hypersurface is a multidimensional space curved in hyperspace (space with the $\mathrm{n}+1$ dimension). In culture, this term describes the phenomenological experience of time, space, and information [10]. One of the main assumptions of responsive architecture is to create a surface which can react to the user's actions so that the 'skin' of the structure can change shape, color and react to changes in the external and internal environment. The HypoSurface project was made as an art-work competition and was exhibited in Venice Biennale International Pavilion in 2000 and BIO, Boston Convention Centre in 2007, among others [11].

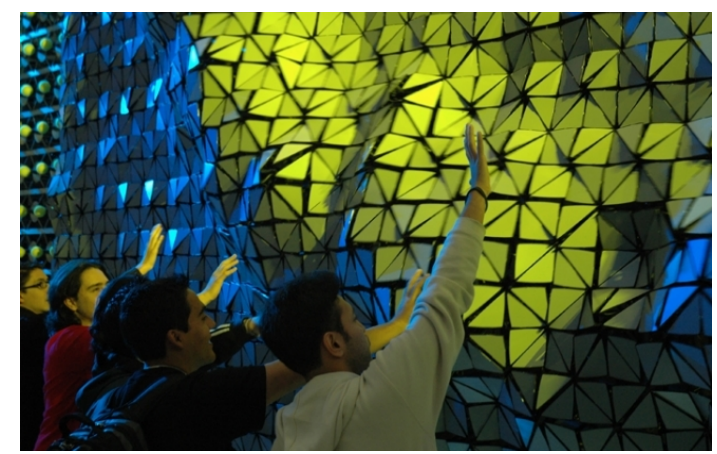

Fig. 4. HypoSurface 'skin' that react to user's actions, source: https://www.musicworks.ca/featuredarticle/visions-sound/hyposurface.

Studio Roosegaarde creates similar solutions, such as the Lotus Dome. The assumption of the project was to transfer the movement of structures to a higher level of sensory and sensual experience. The individual elements were made of the so-called 'lotus foil' and several sensors have been implemented in the structure to detect human movement and temperature changes. The Lotus Dome installation was located in the $17^{\text {th }}$-century Sainte Marie Madeleine church in Lille (France) creating a poetic, interactive play of light and shadows in the interior of the historical building. This structure is an example of a dialogue between traditional architectural solutions and a new direction of responsive architecture [12].

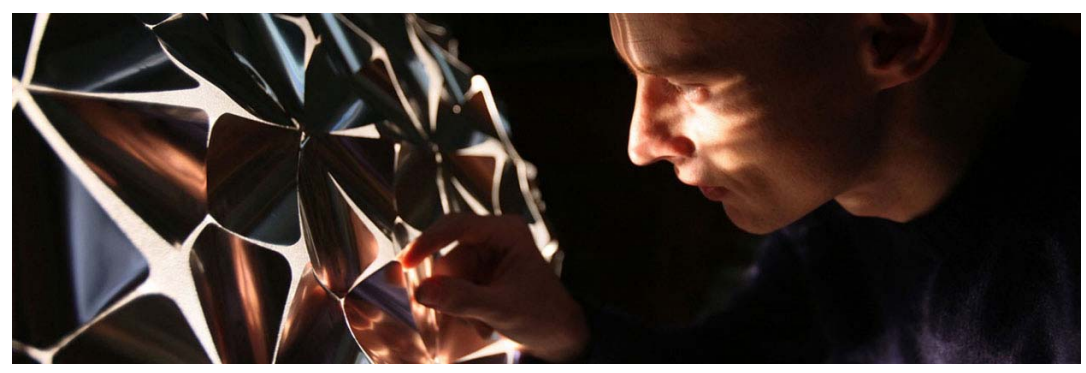

Fig. 5. Lotus Dome structure with elements that react to human touch, source: http://aki.artez.nl/en/ /highlight/daan-roosegaardes-techno-poetry.

\section{Biomimetic and responsive architecture}

Nature adapts to the environmental conditions in the most effective and utilitarian way. Even plants, that we often consider as static, are also making precise movements. Plant movement was the main inspiration for prof. Wilhelm Pfeffer for creating time-lapse films showing the unnoticeable movement of plants and was the subject of numerous studies conducted by 
Charles Darwin. The ingenious solutions occurring in nature have become the inspiration for the emerging new areas of science, i.e. bionic, biomimetic (biomimicry) and biomorphic solutions in architecture and engineering. Nature is defined by strictly functioning rules that can be transposed into the mathematical language. The basic rule discovered by Leonardo Fibonacci is the so-called 'Golden ratio' written by the Greek letter phi $(\varphi=1.61804)$. The golden ratio occurs in nature in, i.e. the construction of inflorescences [13]. From the utilitarian point of view, responsive architecture is mainly being used in shaping the adaptive facades, however, there are more and more solutions that appear in biomimetic and art.
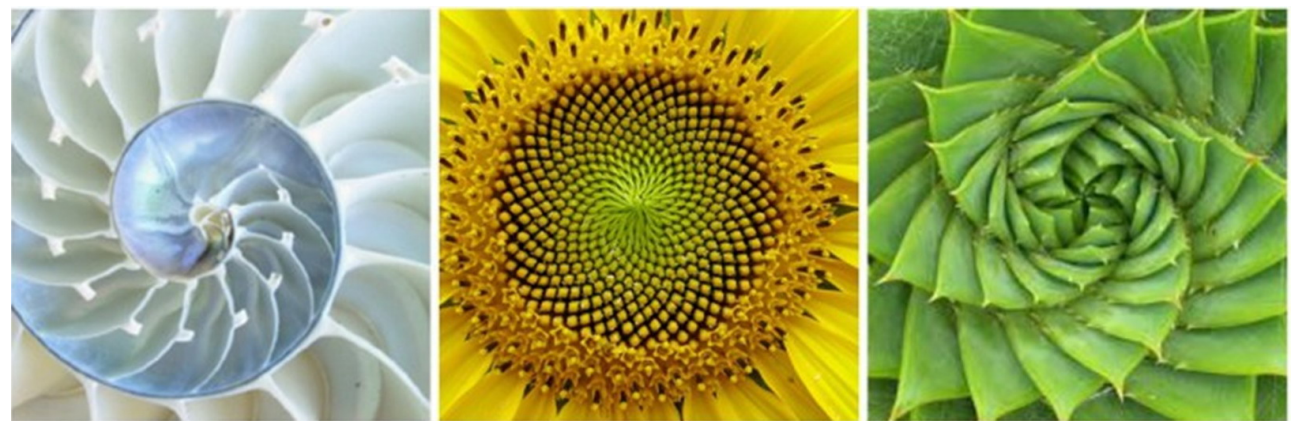

Fig. 6. The examples of 'golden ratio' that occurs in nature, source: http://memolition.com/2014/07/ /17/examples-of-the-golden-ratio-you-can-find-in-nature.

\subsection{The Muscle, Kas Oosterhuis}

The next level of interaction between structure and the user is the Muscle project by Kas Oosterhuis from 2004. K. Oosterhuis is a director of the Hyperbody Research Group (TU Delft) which focuses on implementation of advanced techniques, especially interactive architectural solutions in designing. The Muscle is a completely programmable structure that is enabled to change shape by contracting and relaxing artificial muscles. These solutions are the result of cooperation between Festo and the Hyperbody Group. The Muscle installation has been developed for the Non-standard Architecture Exhibition at Centre Pompidou in Paris. The main construction of the structure is tensile tubes which are the artificial muscles. These muscles change length according to air pressure variations. The skin of the structure is composed of stretchable fabrics used for sports clothing. The Muscle is an experimental structure and a typological hybrid that focuses on a synergetic merger of technology, science, architecture, and art [14]. Kas Oosterhuis is also a designer of the Body Chair that is shown at Dubai Design Days and presented by Dutch Creative Industry.

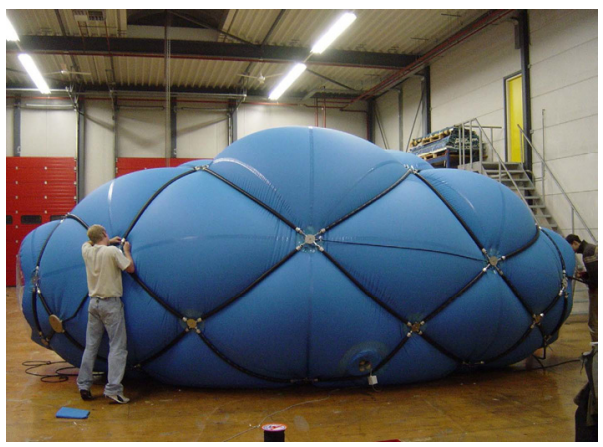

Fig. 7. The Muscle structure, https://www.cca.qc.ca/en/events/3432/in-conversation-with-the-architectsarchaeology-of-the-digital-media-and-machines. 


\subsection{Hylozoic Ground, Philip Beesley}

Philip Beesley is a designer searching for structural forms in responsive architecture and trying to transpose the processes occurring in nature into the engineering solutions. P. Beesley creates light, kinetic, mechanical and interactive systems additionally using microprocessors and sensors. Each subsequent version of his project is a search for a structure that reacts similarly to living organisms. Hence, in his works, a combination of electronic sensors and chemical substances appears. In the years 1995-2017 he created a series of art-structures that reacts to the user's action. One of the most popular is hylozoic series. The structures are a compilation of repetitive para-organic motives. Hylozoic series (i.e. hylozoic ground, soil, veil, grove) is a sequence of installations using evolving elements of interactive mesh. P. Beesley says that he 'likes to think of these material exchanges as being the first stages of metabolic interactions where living functions might take root within matrix' [15]. Hylozoic Ground was selected through a national competition to represent Canada during Venice Biennale in Architecture in 2010. The structure is an 'artificial forest' made of small transparent acrylic meshwork covered with a network of mechanical and interactive fronds. The thousands of lightweight digitally-fabricated components are combined with sensors that react to human presence [16]. B. Beesley also cooperates with Martin Hanczyc, a founder of the Laboratory of Artificial Biology that is a part of the Centre for Integrative Biology (CIBIO) at the University of Trento. Hanczyc $\mathrm{Lab}$ is specialized in interfacial dynamics, robot-chemistry interfaces, modeling of complex chemistry as well as in new bio-inspired materials for architecture and engineering [17].

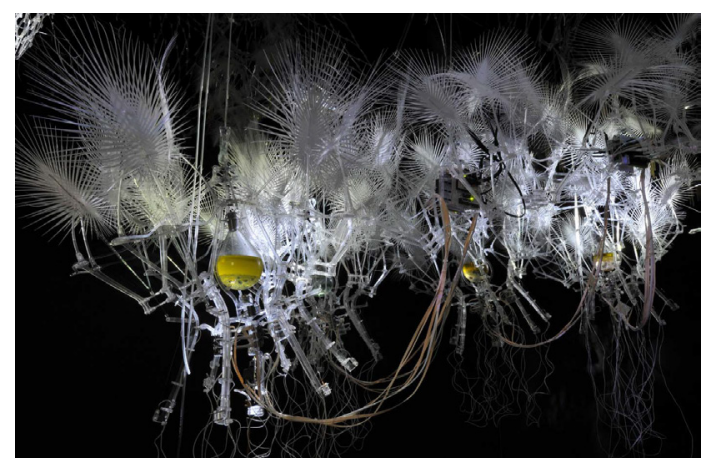

Fig. 8. A part of Hylozoic Ground structure from Canadian Pavilion (Venice Biennale in Architecture), http://www.philipbeesleyarchitect.com/sculptures/0929_Hylozoic_Ground_Venice.

\section{Summary}

One of the first conceptual projects referring to theoretical aspects of responsive architecture was the Fun Palace by Cedric Price, which was also one of the inspirations for Centre Pompidou in Paris. The Fun Palace was something more than a conventional building - a kind of framework and virtual architecture merging art and technology. From about 1964, when the first conceptual drawings of the Fun Palace were created, until 2018, the search for solutions that are beyond the regular understanding of architecture is being continued [18]. Responsive architecture is closely related to the mechanical movement of the structure and the change of the object's properties, because of the influence of external factors. These solutions are not only used in façade and energy-saving systems and in the structures between art and architecture, they can also be used in pro-social activities. In long-term thinking about the role of responsive architecture, this type of architecture can be the basis for shaping objects dedicated to people who lost their houses as a result of the effects of natural disasters or military conflicts. 


\section{References}

1. Ch. Jencks, K. Knopf, (Theories and manifestoes of contemporary architecture, WileyAcademy, 2003)

2. T. d'Estrée Sterk, Autom. Constr., 14 (2005)

3. T. d'Estrée Sterk, (Using Actuated Tensegrity Structures to Produce a Responsive Architecture, Crossroads of Digital Discourse: Proceedings of the 2003 Annual Conference of the Association for Computer Aided Design in Architecture, 2003)

4. http://www.spie-agis.pl/pl/oferta-agis-fire-security/systemy-zarzadzania-budynkami-bms

5. R. C. G. M. Loonen, M. Trčka, D. Cóstola, J. L. M. Hensen, Renewable Sustainable Energy Rev., 25 (2013)

6. B. J. Boer, G. J. Ruijg, R. C. G. M. Loonen, M. Trčka, J. L. M. Hensen, W. Kornaat, (Climate adaptive building shells for the future - optimization with an inverse modelling approach, Proceeding ECEEE Summer Study, 2011)

7. K. Januszkiewicz, M. Zwierzycki, Archivolta, 1 (2013)

8. A. Karanouh, E. Kerber, Innovations in dynamic architecture, The Al-Bahr Towers Design and delivery of complex facades, Journal of Façade Design and Engineering, 3 (2015)

9. M. Addington, D. Schodek, Smart Materials and New Technologies, for architecture and design professions (Elsevier, 2005)

10. K. Januszkiewicz, The area as new cultural conditioning, hypersurface and interactivity, Archivolta, 1 (2014)

11. http://www.hyposurface.org

12. https://www.studioroosegaarde.net/project/lotus

13. https://www.widewalls.ch/golden-ratio-in-contemporary-architecture/

14. K. Oosterhuis, Xin Xia, E. Jap Sam, (Interactive Architecture, 1, 2007)

15. Beesley, O. Khan, (Responsive Architecture, performing instruments, Situated Technologies Pamphlets 4)

16. http://www.philipbeesleyarchitect.com/sculptures/0929_Hylozoic_Ground_Venice/

17. http://www.martinhanczyc.com

18. M. Meagher, (Designing for change: The poetic potential of responsive architecture, Frontiers of Architectural Research, 4, 2015) 